\title{
Stability of coordination polymers in water: state of the art and towards a methodology for nonporous materials
}

\author{
Artur P. Terzyk ${ }^{1} \cdot$ Adam Bieniek $^{1}$ (D) $\cdot$ Paulina Bolibok ${ }^{1} \cdot$ Marek Wiśniewski $^{1} \cdot$ Pilar Ferrer $^{2} \cdot$ Ivan da Silva $^{3}$. \\ Piotr Kowalczyk ${ }^{4}$
}

Received: 24 October 2018 / Revised: 20 November 2018 / Accepted: 28 November 2018 / Published online: 12 December 2018

(c) The Author(s) 2018

\begin{abstract}
A mini review on the study concerning water stability of coordination polymers (CPs) is presented. Next, following the procedure proposed recently by Gelfand and Shimizu (Dalton Trans 45:3668-3678, 2016) the stability of three cysteine (Cys) _ containing CPs is investigated. The stability of studied CPs decreases in the order: $\mathrm{Zn}(\mathrm{Cys})_{2}>\mathrm{Mg}(\mathrm{Cys})_{2}>\mathrm{Ca}(\mathrm{Cys})_{2}$ $\mathrm{H}_{2} \mathrm{O}$. For the latter - never reported before, the structure is additionally determined and it is proved that water is located in the first coordination sphere. It is shown that for nonporous CPs, in contrast to the porous ones, the immersion in water at $20{ }^{\circ} \mathrm{C}$ is more drastic for studied solids than the harsh humid conditions $\left(80{ }^{\circ} \mathrm{C}\right.$ at $90 \%$ R.H.). Finally all materials are assigned to the hydrolytic stability groups and it is concluded that the stability of studied CPs correlates well with the standard reduction potentials. This leads to the conclusion that the application of more inert metal as a node causes larger stability of studied CPs.
\end{abstract}

Keywords Coordination polymer $\cdot$ Degradation $\cdot$ Stability $\cdot$ Cystine $\cdot$ MOF

\section{Introduction}

Stability of a coordination polymer (CP) (called also the metal organic framework-MOF) in water is an important subject due to wide range of CPs application in adsorption, (Han et al. 2013) catalysis, (Mounfield III et al. 2016a,

The $\mathrm{Ca}(\mathrm{Cys})_{2} \mathrm{H}_{2} \mathrm{O}$ structure was deposited in the Cambridge Crystallographic Data Centre - deposition number 1822424.

Electronic supplementary material The online version of this article (https://doi.org/10.1007/s10450-018-9991-9) contains supplementary material, which is available to authorized users.

Adam Bieniek

abieniek@umk.pl

1 Faculty of Chemistry, Physicochemistry of Carbon Materials Research Group, Nicolaus Copernicus University in Torun, Gagarin Street 7, 87-100 Toruń, Poland

2 Diamond Light Source, Harwell Science and Innovation Campus, Chilton, Didcot OX11 0DE, UK

3 Rutherford Appleton Laboratory, ISIS Neutron and Muon Source, Science and Technology Facilities Council, R3 UG.15, Harwell Campus, Didcot OX11 0QX, UK

4 School of Engineering and Information Technology, Murdoch University, Murdoch, WA 6150, Australia b) as biocomposites, (Doonan et al. 2017) membranes, (Li et al. 2015; Wang et al. 2017) and delivery systems (Cychosz and Matzger 2010). In the case of drug delivery systems the instability of a CP can be utilized during the pH-responsible delivery process (Lin et al. 2016). More or less advanced methods have been applied to determine the stability of CPs in water (Lawrence et al. 2016; Guo et al. 2015; Todaro et al. 2016) however, no strictly defined and widely accepted procedure exists. Recently Gelfand and Shimizu (2016) proposed six stages of a MOF exposure for the study of stability in water. In their approach the material is subjected to different conditions starting from the near ambient atmosphere $\left(20{ }^{\circ} \mathrm{C}\right.$ and $20 \%$ of relative humidity) and finishing at the most harshness conditions, i.e., in the boiling water. In contrast, Horwath et al. (2017) proposed a simpler-one step approach for the stability testing, namely dissolution of $20 \mathrm{mg}$ of a CP in $10 \mathrm{ml}$ of water and a CP filtration after $12 \mathrm{~h}$. One should assure that the process of degradation is in fact a hydrolysis. Thus it should be remembered about the possibility of a CP interaction with different compounds present in a solution-for example with a buffer components (to avoid for example, a precipitation of hardly soluble salts). Also the possible influence of oxygen in the atmosphere during stability testing should be considered, as it was shown by theoretical results of Zhang et al. (2017). 
The authors concluded that mixed oxygen/water atmosphere leads to a stronger decrease in a MOF surface area than it was observed for separated oxygen and water atmospheres. This is probably caused by an elongation of the bonds in a $\mathrm{CP}$ by the interactions with a gas mixture.

Bezverkhyy et al. (2016) proposed similar approach to the final stage of Gelfand and Shimizu procedure, and studied the stability of the MIL CPs in water using so called "reflux" method. In this method $100 \mathrm{mg}$ of a CP is suspended in $100 \mathrm{ml}$ of water in an Erlenmeyer flask equipped with a condenser. The solution is heated. Observed decrease in porosity (and the specific surface area) after reflux of fluoride-free CPs in water, was attributed to the blocking of pores by the products of a partial degradation. What is the most important, the XRD data showed no change after the heating in water. The authors concluded that the lack of the changes in the XRD pattern cannot be treated as the proof for the structure stability. Li et al. (2017) reported recently the details of some CPs degradation process in a phosphate buffer explaining the results reported by Bezverkhyy et al. (2016).

Also some methods for testing a CP stability in the atmosphere of the vapours of acidic gases have been proposed. For example Han et al. (2013) first exposed the samples to water and next to $\mathrm{SO}_{2}$ and $\mathrm{NO}_{2}$. Mounfield III et al. (2016a, b) described the mechanism of degradation of a series of cerium and titanium CPs under the influence of water and acidic gases. The role of defected sites located at the edges of particles was shown to be crucial during the decomposition. The process starts by the acidic gas adsorption on the uncoordinated sites and next it is propagated through the particle. Pang et al. (2016) pointed out the importance of crystallographic facets stability in the ZIF- 8 degradation process at the acidic conditions. The mechanism of the process is based on the water adsorption on $\mathrm{Zn}$ (II) and the imidazol linker removal. It was shown that this is easier in the case of (110) facets due to lack of a steric hindrance. The degradation process is additionally assisted by $\mathrm{H}_{2} \mathrm{SO}_{3}$. Also the susceptibility to transformation of the CPs in water can be crucial for stability, as it was shown for two MONT CPs by Taddei et al. (2013).

Considering the general rules of a $\mathrm{CP}$ degradation in water molecular simulation data are very helpful. De Toni et al. (2012) studied the initial stage of IRMOF (a hydrophobic material) decomposition using the MD simulation method. It was shown that the process starts by water adsorption on the metallic cluster and next the linker displacement occurs. This leads to the decrease in the $\mathrm{CP}$ hydration energy barrier. This mechanism was confirmed by experimental data obtained for different CPs (Pang et al. 2016; Al-Janabi et al. 2016). Thus, for example Todaro et al. (2016) using the combined approach (including the EPR studies), established the major stages of a HKUST material degradation due to long time exposure to moisture. At the first stage the reversible water adsorption takes place on the majority $(65 \%)$ of $\mathrm{Cu}-\mathrm{Cu}$ couples. Next, the remaining $35 \%$ of couples adsorb water however, this process is irreversible and leads to the hydrolysis of $\mathrm{Cu}-\mathrm{O}$ bonds. Since the majority of $\mathrm{Cu}^{2+}$ ions remains intact, the HKUST is a very water-resistant material. Zuluaga et al. (2016) studied the process of MOF-74 degradation in water. They showed that hydroxyl created by water splitting is adsorbed on a metal $\left(\mathrm{Zn}^{2+}, \mathrm{Mg}^{2+}, \mathrm{Ni}^{2+}, \mathrm{Co}^{2+}\right)$ cation. The process of water splitting is responsible for the elongation of the metal-linker bond, and this effect depends on the type of a metal cation. Tan et al. (2014) studied the mechanism of water bonding to the MOF-74. It was shown that water is bonded via covalent bonds to the metal cation and via the van der Waals bonds to the linker. Next water dissociation occurs and the dissociation products saturate the metal cation. Interaction of water and $\mathrm{Zn}$ from the MOF-5 nodes is also crucial for this MOF stability (Ming et al. 2015) and this stability strongly depends on the relative humidity. Li et al. (2015) discussed water stability of MOFs applied for the $\mathrm{CO}_{2} / \mathrm{N}_{2}$ separation. This is important subject since the flue gas contains $5-7 \%$ of water. The authors pointed out that the metal-ligand bond strength is crucial and determines the behaviour of a $\mathrm{CP}$ during a ligand displacement by water and a $\mathrm{CP}$ hydrolysis. Thus, for example usually carboxylic-metal bonds are week and are easily broken by water molecules. The authors also concluded that $\mathrm{Cr}-\mathrm{O}, \mathrm{Mg}-\mathrm{O}, \mathrm{Al}-\mathrm{O}$ and $\mathrm{Zn}-\mathrm{O}$ bonds have large stability. It was also concluded that to increase a $\mathrm{CP}$ stability one should apply the cations having as high oxidation degree as possible. It was also shown that the basicity of the ligand is important for the stability of a CP. Jiao et al. (2015) discussed the influence of a metal node on the stability of the MOF-74. It was concluded that possibly the standard reduction potential value (larger for $\mathrm{Ni}^{2+}$ and $\mathrm{Co}^{2+}$ than for $\mathrm{Mg}^{2+}$ ) leading to weaker reducing properties of $\mathrm{Ni}^{2+}$ than $\mathrm{Mg}^{2+}$ causes larger stability of Ni-MOF-74 than $\mathrm{Mg}$ MOF-74. Thus it was also concluded that the application of more inert metal as a node leads to larger stability of many other MOFs. Some results (Jiao et al. 2015) confirm this conclusions because the stability of Mg-MOF-74 increases after introduction of $\mathrm{Ni}^{2+}$ and $\mathrm{Co}^{2+}$.

However, other simulation data lead to more complicated mechanism of a CP degradation than simple water adsorption and a linker displacement. Bellarosa et al. (2012) discussed the water resistance of $\mathrm{Zn}^{2+}, \mathrm{Be}^{2+}$ and $\mathrm{Mg}^{2+}$ IRMOF-1 structures using the MD approach. It was concluded that the resistance to water is a combination of different $\mathrm{CP}$ properties and depends on the core rigidity, a $\mathrm{CP}$ flexibility and the strength of coordination of a metal centre by oxygen. Thus, stability depends not only on the type of a metal node but also on the linker (DeCoste et al. 2013). At acidic conditions $(\mathrm{HCl})$ the carboxylate groups can be protonated and some bonds between double rings in linkers can 
be broken (DeCoste et al. 2013). Tan et al. (2015) presented very important review and in house experiment on the state of water in a series of isostructural CPs. The stability of CPs with saturated metal centres was shown to be dependent on the strength of metal-oxygen bond and the stability of aminacomplexes. The authors also discussed the methods improving a CP stability in water. Piscopo et al. (2015) showed that the coordination of a metal cation $\left(\mathrm{Zr}^{4+}\right.$ in this case) is crucial for the stability and the preparation conditions influencing this coordination of a cation can change a CP stability. The authors used different methods of a CP synthesis and tested the stability in the $\mathrm{HCl}$ (at three $\mathrm{pH}$ levels). The XRD data showed no influence of $\mathrm{HCl}$, and the reduction of the size of crystals in $\mathrm{HCl}$ was the same as in water. Lu et al. (2014) performed a series of DFT calculations and concluded that not always a CP stability increases with the coordination number of a metal, and the strength of $\mathrm{M}-\mathrm{L}$ bond is crucial for this stability. This strength can be estimated by the calculation of the $p K_{a}$ for the protonanted ligand and the charge of a ligand oxygen atom. Howarth et al. reviewed the most important subjects related to CPs chemical, thermal and mechanical stability (Howarth et al. 2016) i.e., resistance of the structure to degradation. The authors pointed out the lack of standard procedures of stability assessment making the comparison of the results of different studies problematic. Among the most important factors determining a CP stability the authors mentioned: a strength of a linker-metal bond, a shielding of the metal cation by linkers, a metal cation oxidation state, a linker hydrophobicity, application of hydrophobic substituents leading to the reduction of a $\mathrm{CP}$ porosity and in this way decreasing the size of water clusters inside. Mounfield III et al. (2016a, b) also pointed out the role of $\mathrm{H}_{2} \mathrm{SO}_{3}$ in MIL-125 degradation showing that the introduction of $\mathrm{NH}_{2}$ groups stabilizes the CP structure. Jasuja et al. (2012) reported very interesting approach considering the influence of linkers on the stability of isostructural DMOF materials in water. It was concluded that the introduction of nonpolar groups into a CP structure increases stability and in contrast, the incorporation of a polar group leads to stability decrease. Considering reversibility of degradation MD simulation results show that the both processes: the attack of water molecules on a cation in a CP structure and a linker displacement can be reversible (De Toni et al. 2012). Also initial stages of decomposition can be for some CPs reversible (DeCoste et al. 2013), while the latter stages of HKUST-1 degradation are irreversible (Todaro et al. 2016). There are also reports showing that reversibility/irreversibility depends on relative humidity (Ming et al. 2015; Tan et al. 2014).

Taking into account discussed above results one can conclude that the process of CPs decomposition is very complicated, and the general procedure for the study of the stability in water does not exist. To get some regularities describing
$\mathrm{CP}$ degradation we decided to start a basic study on the $\mathrm{CP}$ decomposition using three nonporous materials, possessing the same linker (Cys) and different metal nodes, having the same oxidation degree but different coordination numbers. To do this a new $\mathrm{Ca}^{2+}$-containing $\mathrm{CP}$ was synthesized and studied together with two freshly reported materials possessing $\mathrm{Zn}^{2+}$ (Ferrer et al. 2014) and $\mathrm{Mg}^{2+}$ (Wiśniewski et al. 2018) in their structures. Since all the three materials are nonporous, the next aim of our study is to check the procedure proposed by Gelfand and Shimizu (2016) for the study of the stability of nonporous CPs. Since the original procedure was proposed for porous CPs we show below, that for nonporous solids the levels of harshness of exposure can be different. We also want to find the general rules causing observed stability of MOFs in water allowing to assign the materials to respective stability group. Additionally, we check the applicability of the XRD and ATR methods for the CP stability testing.

\section{Experiment}

\subsection{CPs synthesis}

A new procedure of $\mathrm{Zn}(\mathrm{Cys})_{2}$ synthesis is proposed for the purpose of this study (see the Electronic Supplementary Material for details). The synthesis of $\mathrm{Mg}(\mathrm{Cys})_{2}$ was performed using the same method as previously (Wiśniewski et al. 2018 - see the Electronic Supplementary Material for details). To perform the synthesis of $\mathrm{Ca}(\mathrm{Cys})_{2} \cdot \mathrm{H}_{2} \mathrm{O}$, Cys $(2.4 \mathrm{~g})$ and $\mathrm{KOH}(1.69 \mathrm{~g})$ were dissolved in $150 \mathrm{ml}$ solution of $\mathrm{MeOH}$ and $\mathrm{H}_{2} \mathrm{O} 2: 1$ (v:v). Separately $\mathrm{Ca}\left(\mathrm{NO}_{3}\right)_{2} \cdot 4 \mathrm{H}_{2} \mathrm{O}$ $\left(3.542 \mathrm{~g}\right.$ ) was dissolved in $150 \mathrm{ml}$ similar $\mathrm{MeOH} / \mathrm{H}_{2} \mathrm{O}$ solution. Both solutions were mixed and stirred for $1 \mathrm{~h}$ at the room temperature. Resulting precipitate was washed several times with methanol and finally with deionized water. The obtained precipitate was centrifuged and gained thus white powder was dried at $50{ }^{\circ} \mathrm{C}$ in vacuum oven $(24 \mathrm{~h})$.

\subsection{Crystal structure determination and Rietveld refinement}

The procedure of $\mathrm{Zn}(\mathrm{Cys})_{2}$ and $\mathrm{Mg}(\mathrm{Cys})_{2}$ crystal structure determination was described previously (Ferrer et al. 2014; Wiśniewski et al. 2018). However, because the $\mathrm{Ca}(\mathrm{Cys})_{2}$ is a new CP, below we describe in details the procedure of its structure determination. The angular positions of the first 25 reflections (up to about $42^{\circ} 2 \theta$ ) were determined using the peak search option implemented in Topas Academic v5 program (http://www.topas-academic.net/). These positions were used to index the diffraction pattern into 
the monoclinic system, yielding a cell with a volume of $608.7 \AA^{3}$ and cell parameters $a=8.6924 \AA, b=6.5233 \AA$, $c=11.4779 \AA$ and $\beta=69.260^{\circ}$. The EXPO2004 program (Altomare et al. 2004) was used for the determination of the correct space-group, this software uses a statistical algorithm to determine the most probable extinction group (Altomare et al. 2005). For $\mathrm{Ca}(\mathrm{Cys})_{2} \cdot \mathrm{H}_{2} \mathrm{O}$ compound, the highest probability was assigned to the extinction group $C 1-1$, which was confirmed by visual inspection of the systematic absences. Space group $C 2$ was then selected for structure solution procedure. Crystal structure solution was achieved from Simulated Annealing calculations, using Topas Academic v5 program. A template of the Cys structural fragment and a $\mathrm{Ca}$ atom were introduced as input for calculations and the Cys molecule template was built using the $z$-matrix description, using bond distances, angles and torsions from the L-Cysteine crystal structure (Harding and Long 1968; CCDC Identifier 1204446). During the calculations, the observed and calculated intensities were compared in the $2 \theta$ range from $7.5^{\circ}$ to $69^{\circ}$, the Cys fragment could translate and rotate randomly (bond distances and angles were kept fix, while the torsion angles could be randomly modified) and the position of $\mathrm{Ca}$ atom was free to change. During a first Simulated Annealing attempt, $\mathrm{Ca}$ atom was found to be sitting on a special position, so subsequent calculations were performed fixing the $\mathrm{Ca}$ atom position to the twofold rotation axis. After $\sim 40,000$ iteration trials, the agreement factor from the Simulated Annealing calculations was $R_{\mathrm{wp}}=8.96 \%$. A Rietveld refinement (Rietveld 1969) of the obtained crystal structure was carried out, but little improvement was achieved. A difference Fourier map showed a residual electronic density peak located at $\sim 2.4 \AA$ from the $\mathrm{Ca}$ atom, which was assigned to a water molecule and hydrogen atoms were then introduced in Topas at their
Table 1 Crystallographic data and Rietveld refinement summary for the compound $\mathrm{Ca}(\mathrm{Cys})_{2} \cdot \mathrm{H}_{2} \mathrm{O}$

\begin{tabular}{ll}
\hline Crystallographic data & \\
Formula & $\mathrm{Ca}\left(\mathrm{C}_{3} \mathrm{H}_{5} \mathrm{NO}_{2} \mathrm{~S}\right)_{2} \cdot \mathrm{H}_{2} \mathrm{O}$ \\
Formula weight $\left(\mathrm{g} \mathrm{mol}^{-1}\right)$ & 396.38 \\
Crystal system & Monoclinic \\
Space group & $C 2$ \\
Unit cell dimensions & \\
$a(\AA)$ & $8.6905(3)$ \\
$b(\AA)$ & $6.52263(19)$ \\
$c(\AA)$ & $11.4730(3)$ \\
$\beta\left({ }^{\circ}\right)$ & $69.2852(16)$ \\
Cell volume $\left(\AA^{3}\right)$ & $608.30(3)$ \\
$\mathrm{Z}$ & 2 \\
Radiation type & $\mathrm{X}$-ray \\
Diffractometer & PANalytical X'Pert Pro \\
Data collection mode & Reflection \\
Wavelength $(\AA)$ & Cu Ko $\alpha_{1}$ \\
Rietveld refinement & \\
$R_{p}(\%)$ & 3.30 \\
$R_{w p}(\%)$ & 4.52 \\
$R_{\text {exp }}(\%)$ & 3.06 \\
$R_{B}(\%)$ & 2.52 \\
Goodness-of-Fit & 1.47 \\
\hline
\end{tabular}

calculated positions with Olex2 program (Dolomanov et al. 2009). During the Rietveld refinement, the positions of $\mathrm{H}$ atoms were restrained to that of their riding atom, owing to the possibility of deformation or rotation of the molecular fragments, the positions of $\mathrm{H}$ atoms were recalculated several times during the refinement procedure before it converged. The final Rietveld refinement included the atomic coordinates of all atoms, three different isotropic temperature factors were introduced for the
Fig. 1 Final Rietveld refinement plot, showing the experimental (red circles), calculated (black line) and difference profiles (blue line), green tick marks indicate reflection positions. (Color figure online)

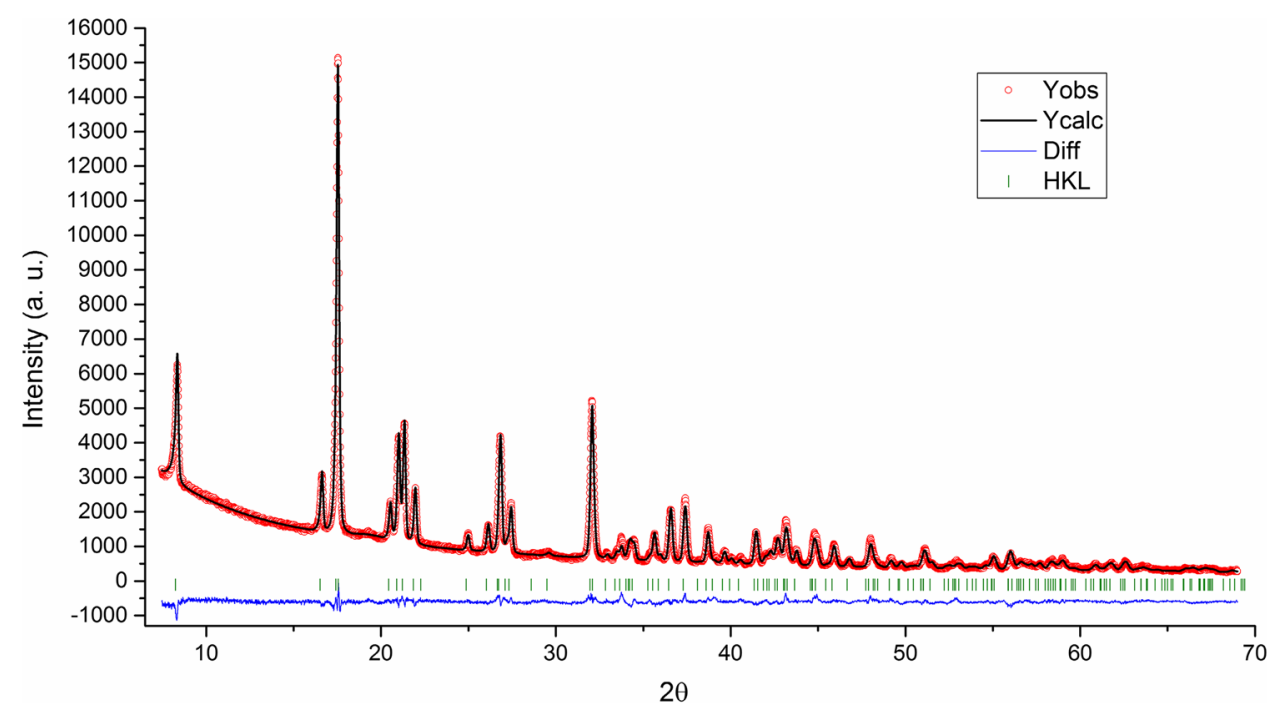




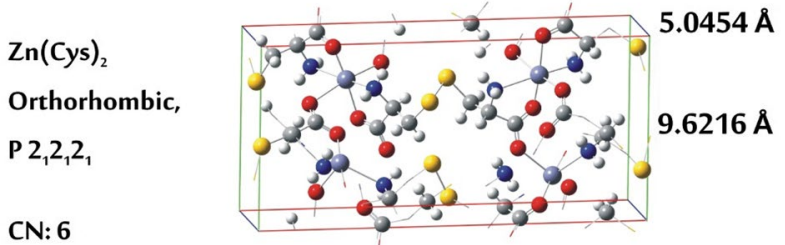

$20.182 \AA$

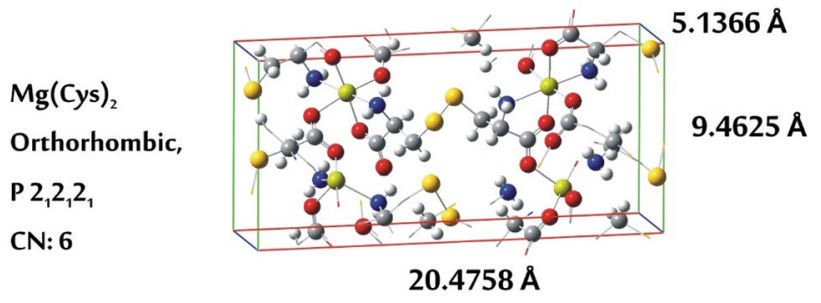

$\mathrm{Ca}(\mathrm{Cys})_{2} \mathrm{H}_{2} \mathrm{O}$

Monoclinic,

C2

$\mathrm{CN}: 7$

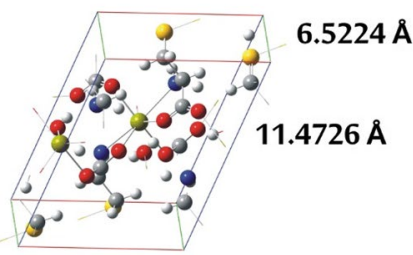

$8.6906 \AA$

Fig. 2 The structures of studied CPs, space symmetry groups (SSG) and coordination numbers $(\mathrm{CN})$

structure refinement, one for $\mathrm{C}, \mathrm{O}, \mathrm{N}$, and $\mathrm{S}$ atoms from Cys molecular fragment, one for the $\mathrm{Ca}$ atom and another one for the water molecule. The experimental diffraction peak shapes were fitted using the Thompson-Cox-Hastings Pseudo-Voigt function (Thompson et al. 1987) and a Chebychev polynomial was used to model the background. On the final Rietveld fit, there were 67 adjustable parameters (scale factor, zero shift, atomic coordinates, temperature factors, unit-cell parameters and peak-shape parameters).

\subsection{Testing the stability of CPs in water}

The samples of CPs (100 mg) were exposed to $(24 \mathrm{~h})$ : $20{ }^{\circ} \mathrm{C}-20 \%$ R.H. (stage 1), $25^{\circ} \mathrm{C}-50 \%$ R.H. (stage 2), $50{ }^{\circ} \mathrm{C}-50 \%$ R.H. (stage 3), $80{ }^{\circ} \mathrm{C}-90 \%$ R.H. (stage 4), $20{ }^{\circ} \mathrm{C}$-immersion in $\mathrm{H}_{2} \mathrm{O}$ (stage 5 ), $100{ }^{\circ} \mathrm{C}$-immersion in $\mathrm{H}_{2} \mathrm{O}$ (stage 6). (for the details see the Electronic Supplementary Material). The samples were subjected to XRD and ATR-FTIR analysis. For selected materials $\mathrm{N}_{2}$ adsorption-desorption isotherms were also measured, and the exposure times were also changed (see Table 2).

\subsection{ATR-FTIR study}

The Fourier transform infrared spectra (FTIR) measurements after samples drying were accomplished by Bruker Vertex 70 infrared spectrophotometer using Platinum diamond ATR techniques in the frequency range $60-4000 \mathrm{~cm}^{-1}$. The spectra (128 scans) were collected after evacuation of the measurement chamber below $100 \mathrm{~Pa}$.

\subsection{ASA study of degradation in water}

A calibration curve was prepared based on the preparation of salt solutions $\left(\mathrm{Zn}\left(\mathrm{NO}_{3}\right)_{2} \cdot 6 \mathrm{H}_{2} \mathrm{O}, \mathrm{Mg}\left(\mathrm{NO}_{3}\right)_{2} \cdot 6 \mathrm{H}_{2} \mathrm{O}\right.$ and $\left.\mathrm{Ca}\left(\mathrm{NO}_{3}\right)_{2} \cdot 4 \mathrm{H}_{2} \mathrm{O}\right)$ possessing known concentrations of cations $\left(0.5-10 \mathrm{mg} / \mathrm{dm}^{3}\right)$ in deionized water. The stability was checked by the dissolving of $6 \mathrm{mg}$ of a CP in $160 \mathrm{ml}$ of deionized water. $2 \mathrm{ml}$ of the sample solution were analysed using the ASA method.
Table 2 The results of studied CPs degradation for stages 1 , 3 and 4 (ST-1, ST-3 and ST-4) in water vapour by using ATRFTIR and XRD methods

\begin{tabular}{|c|c|c|c|c|c|c|c|}
\hline \multirow{3}{*}{$\begin{array}{l}\text { Conditions } \\
\text { temp./humidity } \\
\left({ }^{\circ} \mathrm{C} / \%\right)\end{array}$} & \multirow[t]{3}{*}{ Time (h) } & \multicolumn{3}{|c|}{ ATR-FTIR } & \multicolumn{3}{|l|}{ XRD } \\
\hline & & $\mathrm{Zn}(\mathrm{Cys})_{2}$ & $\operatorname{Mg}(\text { Cys })_{2}$ & $\mathrm{Ca}(\mathrm{Cys})_{2} \cdot \mathrm{H}_{2} \mathrm{O}$ & $\mathrm{Zn}(\mathrm{Cys})_{2}$ & $\operatorname{Mg}(\mathrm{Cys})_{2}$ & $\mathrm{Ca}(\mathrm{Cys})_{2} \mathrm{H}_{2} \mathrm{O}$ \\
\hline & & Stability & Stability & Stability & Stability & Stability & Stability \\
\hline ST-1: $20^{\circ} \mathrm{C} / 20 \%$ & 12 & + & + & + & + & + & + \\
\hline ST-3: $50^{\circ} \mathrm{C} / 50 \%$ & 1 & + & + & + & + & + & + \\
\hline ST-3: $50^{\circ} \mathrm{C} / 50 \%$ & 4 & + & + & + & + & + & + \\
\hline ST-3: $50^{\circ} \mathrm{C} / 50 \%$ & 12 & + & + & + & + & + & + \\
\hline ST-3: $50{ }^{\circ} \mathrm{C} / 50 \%$ & 24 & + & + & + & + & + & + \\
\hline ST-3: $50{ }^{\circ} \mathrm{C} / 50 \%$ & 96 & + & + & + & + & + & $\pm^{*}$ \\
\hline ST-4: $80^{\circ} \mathrm{C} / 90 \%$ & 2 & + & + & + & + & + & + \\
\hline ST-4: $80^{\circ} \mathrm{C} / 90 \%$ & 6 & + & + & + & + & + & + \\
\hline ST-4: $80^{\circ} \mathrm{C} / 90 \%$ & 24 & + & + & + & + & + & + \\
\hline ST-4: $80^{\circ} \mathrm{C} / 90 \%$ & 48 & + & + & + & + & + & $\pm^{*}$ \\
\hline ST-4: $80^{\circ} \mathrm{C} / 90 \%$ & 96 & + & + & - & + & + & - \\
\hline
\end{tabular}

$*_{ \pm}$intensity loss but main peaks still remain 
Fig. 3 FTIR (upper panel) and XRD (bottom panel) of initial $\mathrm{Zn}(\mathrm{Cys})_{2}$ structure and after treatment stages ST-5 and ST-6
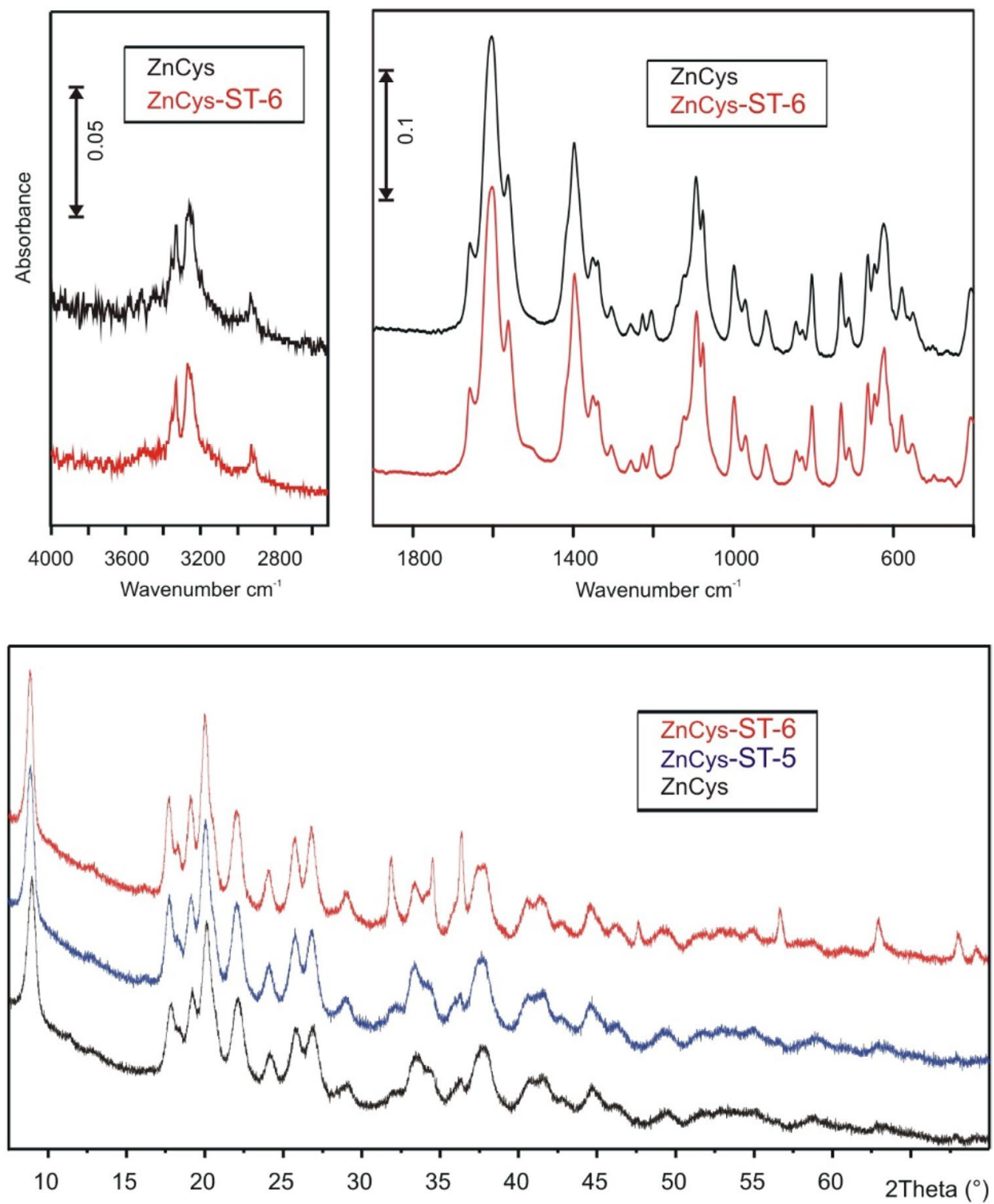

\section{Results and discussion}

\subsection{The results of structural studies}

Figure 1 shows the plot of the final Rietveld fit for a new compound $\mathrm{Ca}(\mathrm{Cys})_{2} \cdot \mathrm{H}_{2} \mathrm{O}$, while Table 1 reports crystallographic and refinement-related data.

One can observe that the fit between the experimental and calculated patterns is very good. The same situation was observed for the two remaining CPs (Ferrer et al. 2014; Wiśniewski et al. 2018). In Fig. 2 we collect all the structures of studied CPs. The coordination number $(\mathrm{CN})$ for $\mathrm{Zn}^{2+}$ and $\mathrm{Mg}^{2+}$ is equal to 6, while for $\mathrm{Ca}^{2+}$ it is equal to 7 . Similar CNs have been reported in literature for other CPs (Wang et al. 2014; Katz et al. 1996).

\subsection{The results of stability tests}

Table 2 collects the results obtained during the stability tests of studied CPs (stages 1, 3 and 4) using the ATRFTIR and XRD techniques. One can observe, that the both methods show the stability of $\mathrm{Zn}(\mathrm{Cys})_{2}$ and $\mathrm{Mg}(\mathrm{Cys})_{2}$ CPs. Application of the ATR-FTIR technique shows that the $\mathrm{Ca}(\mathrm{Cys})_{2} \cdot \mathrm{H}_{2} \mathrm{O}$ is unstable only at the ST-4 and after $96 \mathrm{~h}$ of treatment (with the rise in surface area-see Table S1 in the Electronic Supplementary Material). In contrast the results of XRD show that the decomposition of $\mathrm{Ca}(\mathrm{Cys})_{2} \cdot \mathrm{H}_{2} \mathrm{O}$ starts at the ST-3 after $96 \mathrm{~h}$. Some representative spectra together with the observed nuances are discussed below.

In Figs. 3, 4, 5 the upper panels present the ATR-FTIR spectra of the tested CPs. The lack of characteristic signals 
Fig. 4 FTIR (upper panel) and XRD (bottom panel) of initial $\operatorname{Mg}(\mathrm{Cys})_{2}$ structure and after the treatment stage ST-4
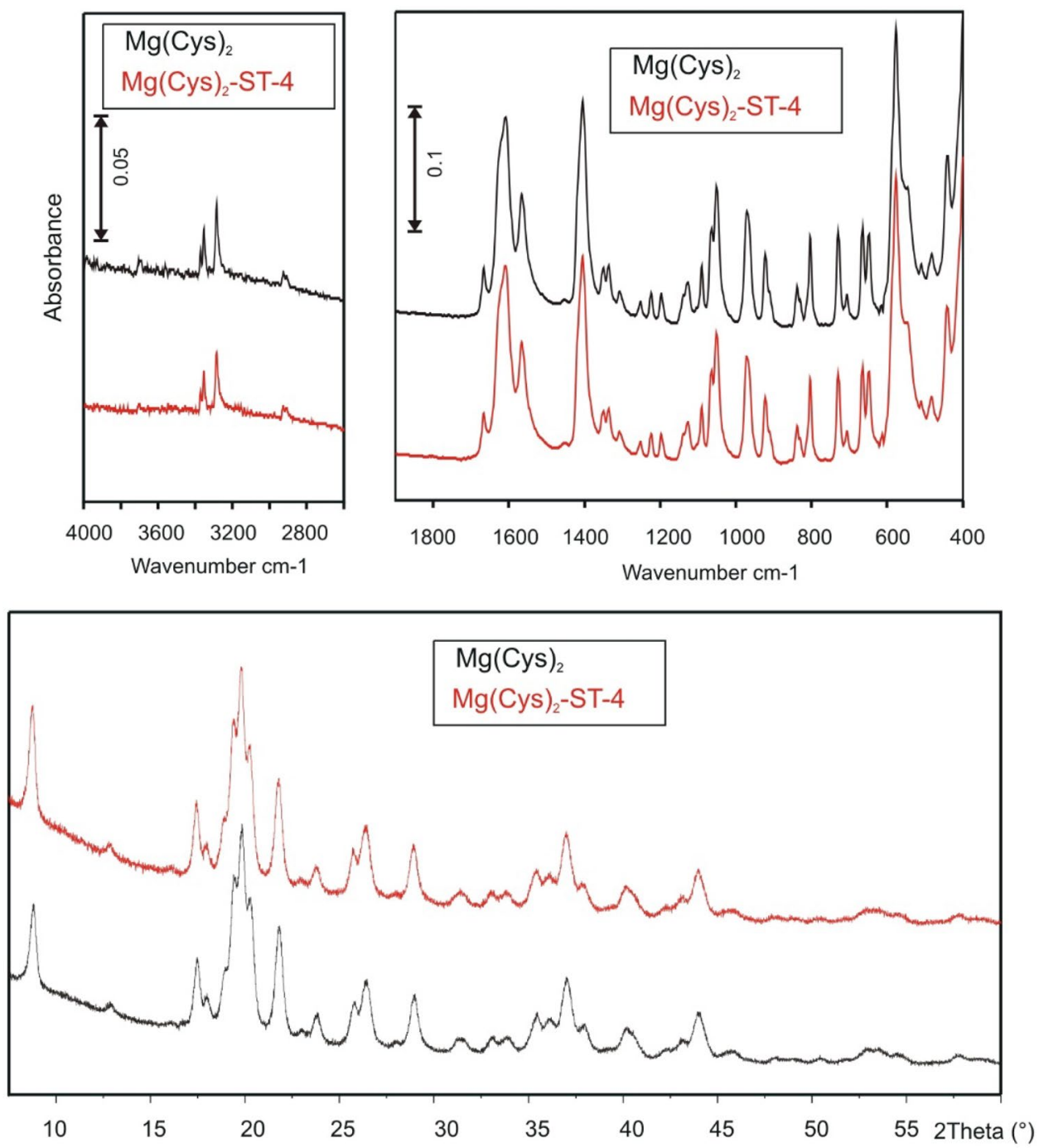

for amino acids hydrogen bonds are visible in the each FTIR spectrum visible as a broad and mutually overlapping band in the $\mathrm{OH} / \mathrm{NH}$ stretching spectral range of 3300 up to $2300 \mathrm{~cm}^{-1}$ as well as in the bending range $\sim 1500 \mathrm{~cm}^{-1}$. Thus the formation of the CP causes the structure to lose the hydrogen bonds revealing the $\nu(\mathrm{NH})$ asymmetric and symmetric signals at 3350 and $3250 \mathrm{~cm}^{-1}$ and $\delta\left(\mathrm{NH}_{2}\right)$ at $1564 \mathrm{~cm}^{-1}$, respectively. Interestingly, in the $\mathrm{Zn}(\mathrm{Cys})_{2}$ as well as in the $\mathrm{Mg}(\mathrm{Cys})_{2}$ structures, there are no $v(\mathrm{OH})$ in the IR spectra meaning that in the obtained CPs carboxyl groups are involved in the metal ion nodes. The broad band in the $\nu(\mathrm{OH})$ of $\mathrm{Ca}(\mathrm{Cys})_{2} \cdot \mathrm{H}_{2} \mathrm{O}$ is due to water molecules incorporated into the structure (see Fig. 5), what most probably is one of the possible reasons of the lowest stability of this structure (Katz et al. 1996).

The absence of $\nu(\mathrm{OH})$ as well as the presence of sole and isolated $\nu(\mathrm{NH})$ indicates a stiffness of the $-\mathrm{NH}_{2}$ group due to $\mathrm{H}_{2} \mathrm{~N}$-cation bonding. The hypothesis is completely in line with the proposed by Ferrer et al. (2014) for the $\mathrm{Zn}(\mathrm{Cys})_{2}$ metallic nodes formation through $\mathrm{O}$ (from $\mathrm{COO}^{-}$group)$\mathrm{Zn}^{2+}-\mathrm{N}$ (from $\mathrm{NH}_{2}$ group). The formation of metal-Cys bonds is observed also as the appearance of the band near $915 \mathrm{~cm}^{-1}$ responsible for the $\nu(\mathrm{C}-\mathrm{O})$ vibrations in $\mathrm{C}-\mathrm{O}-\mathrm{Me}$ formations.

The XRD patterns collected in Figs. 3, 4, 5 show sharp signals and what is important, the absence of amorphous phase signals, confirming the studied CPs crystallinity. The $\mathrm{XRD}$ results for $\mathrm{Zn}(\mathrm{Cys})_{2}$ correspond completely to the reported previously by Ferrer et al. (2014). While analyzing the degradation of tested nonporous structures, the data collected in Fig. 3 show that $\mathrm{Zn}(\mathrm{Cys})_{2}$ is stable up to the ST-5 (see Table 2). Its partial decomposition after the ST-6 causes the appearance of $\mathrm{ZnO}$, observable only in the XRD analysis. The decrease in the value of BET surface area is observed simultaneously (see Table S1 in the Electronic Supplementary Material). Thus it can be concluded, that it is of decisive importance to combine different spectroscopic methods, as here, where $\mathrm{ZnO}$ is invisible in the FTIR 
Fig. 5 FTIR (upper panel) and XRD (bottom panel) of initial $\mathrm{Ca}(\mathrm{Cys})_{2} \cdot \mathrm{H}_{2} \mathrm{O}$ structure and after the treatment stage ST-4
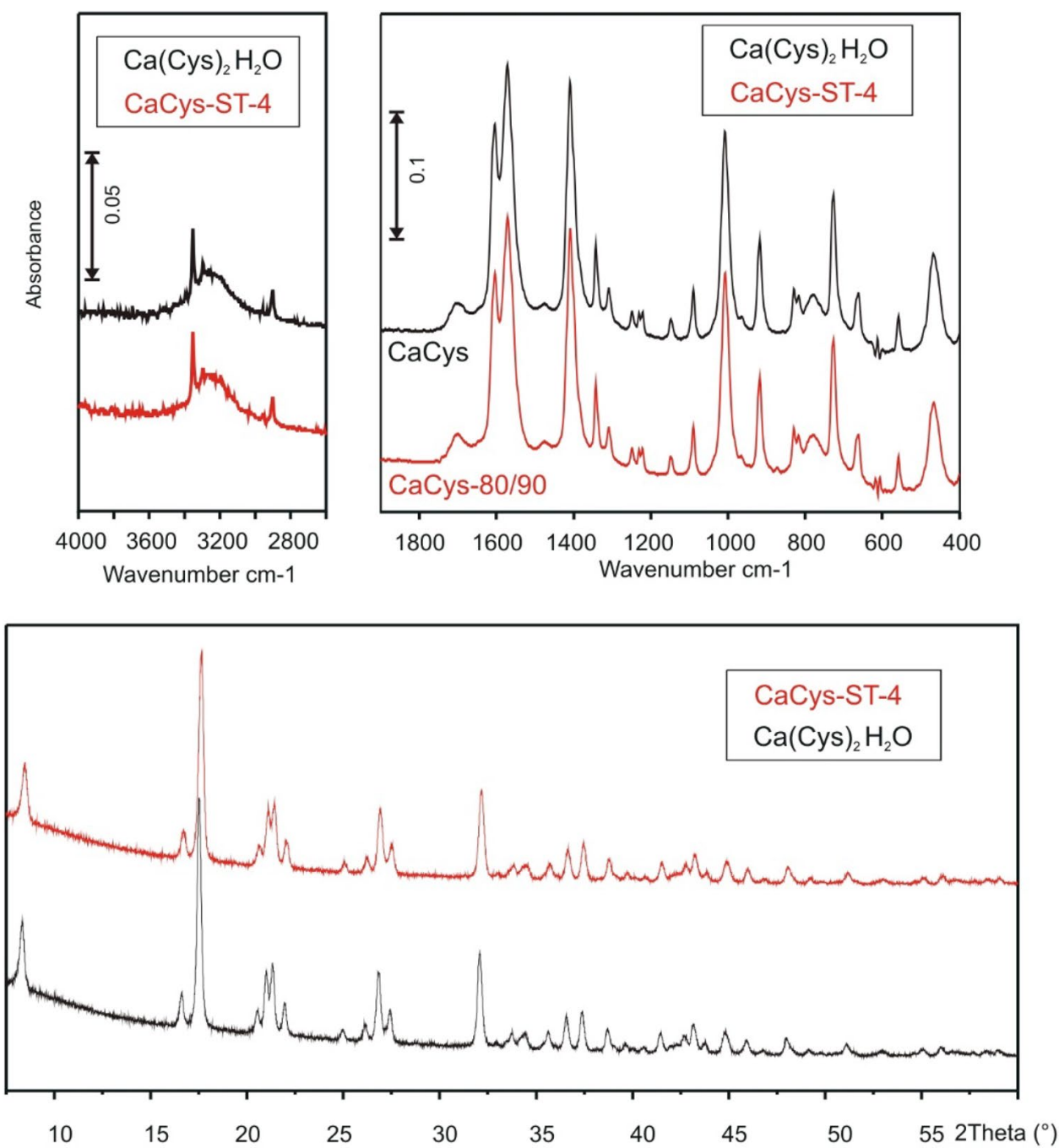

analysis due to the low intensity of the product in comparison to the substrate matrix.

The data collected in Fig. 4 reveal the stability of the $\mathrm{Mg}(\mathrm{Cys})_{2}$ even at the ST-4 (see Table 1). However, after the immersion in water already at $20{ }^{\circ} \mathrm{C}$ (ST-5) the complete degradation occurs.

The most interesting results were observed for the case of $\mathrm{Ca}(\mathrm{Cys})_{2} \mathrm{H}_{2} \mathrm{O}$ samples. During $24 \mathrm{~h}$ treatment in the ST-3 (see Table 1) its stability was similar to $\mathrm{Mg}(\mathrm{Cys})_{2}$ sample. However, prolongation of tested period up to $96 \mathrm{~h}$ caused degradation. Thus it is evident that $24 \mathrm{~h}$ testing time proposed as the initial time for testing of porous CPs (Gelfand and Shimizu 2016) for the non-porous structures must be extended at least up to $96 \mathrm{~h}$ (Fig. 6).

Taking into account the proposal of Gelfand and Shimizu (2016) we can now assign studied CPs into the stability groups taking into account the results from Table 1, S1 and Fig. 3, 4, 5, 6. Thus $\mathrm{Zn}(\mathrm{Cys})_{2}$ shows 5A-6C type of stability because it is stable at the ST-5 with conservation of crystallinity and surface area, and decomposes at the ST-6 with retention of some order but with the decrease in surface area. $\mathrm{Mg}(\mathrm{Cys})_{2}$ belongs to $4 \mathrm{~A}$ group, since it is stable at the ST-4 and totally soluble at the ST-5. Finally, the $\mathrm{Ca}(\mathrm{Cys})_{2} \mathrm{H}_{2} \mathrm{O}$ belongs to $3 \mathrm{~A}-4 \mathrm{C}$ groups, since it is stable at the ST-3 with retention of crystallinity and porosity and decomposes at the ST-4 with the retention of some order but without surface area conservation.

\subsection{Kinetics of degradation in water}

Figure 7 collects the results of degradation kinetics at $20^{\circ} \mathrm{C}$ (ST-5). One can observe the stability of $\mathrm{Zn}(\mathrm{Cys})_{2}$ and relatively fast degradation for the two remaining samples.

As it was shown above, the $\mathrm{CN}$ value of a metal cation is not responsible for the stability of studied CPs. Moreover, the presence of water in the first coordination shell can decrease the stability of $\mathrm{Ca}(\mathrm{Cys})_{2} \cdot \mathrm{H}_{2} \mathrm{O}$. However, taking into account the results of Jiao et al. (Jiao et al. 2015) considering the stability of MOF-74 CPs (see Introduction) we tried to correlate the values of standard reduction potentials of 
Fig. 6 FTIR (upper panel) and XRD (bottom panel) of $\mathrm{Ca}(\mathrm{Cys})_{2} \cdot \mathrm{H}_{2} \mathrm{O}$ structure during the treatment stage ST-4. It is evident that $24 \mathrm{~h}$ is too short period

Fig. 7 The results of degradation kinetics at $20^{\circ} \mathrm{C}$ (ST-5); $c$ and $c_{\max }$ are the concentration and the maximum concentration of a metal cation determined using the ASA, respectively. The correlation between standard reduction potentials and the $c / c_{\max }$ values at selected times (1 min-crosses, 5 min-triangles, 10 min-circles)
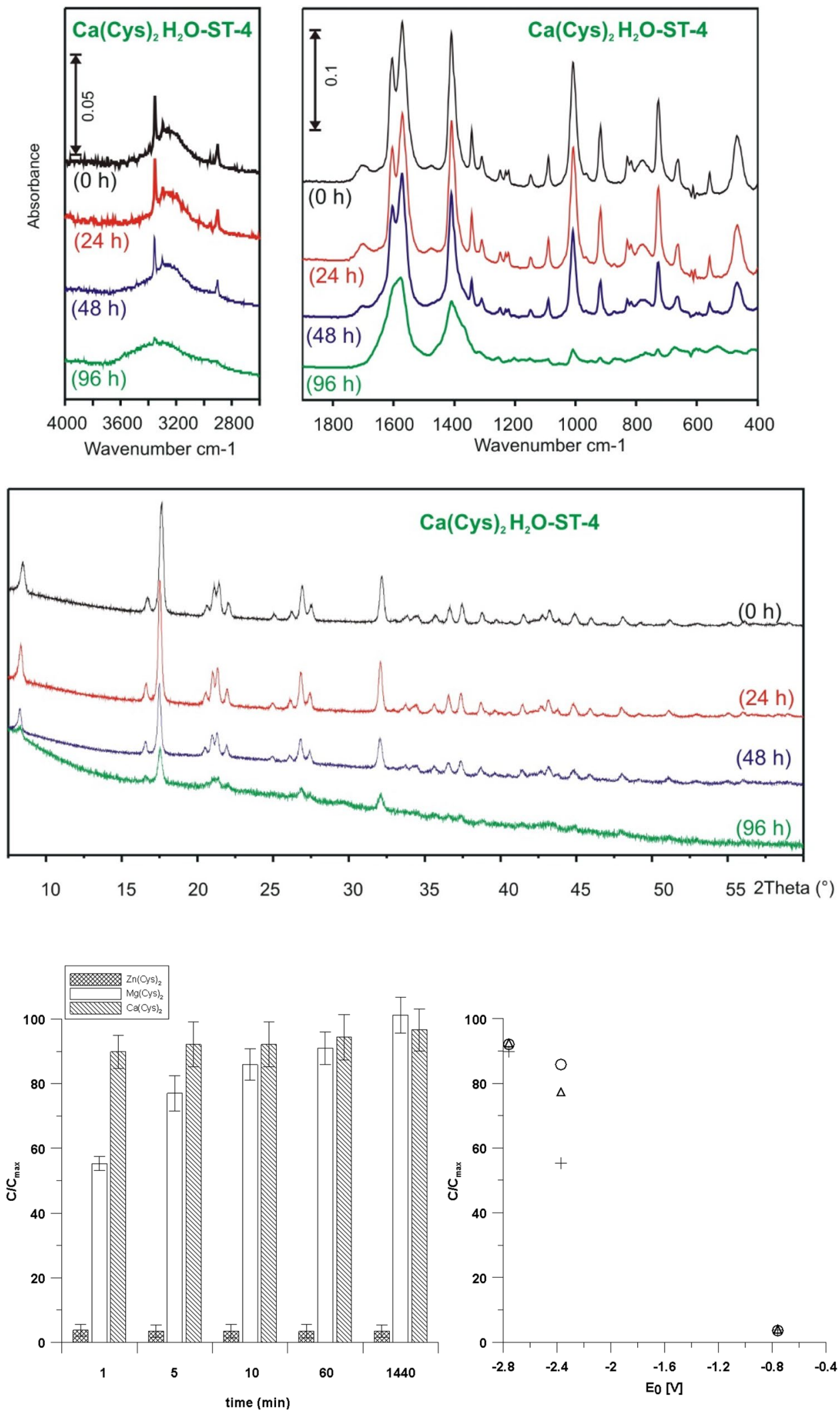
metal nodes $\left(\mathrm{E}_{\mathrm{Zn} / \mathrm{Zn}}{ }^{2+}=-0.76 \mathrm{~V}, \mathrm{E}_{\mathrm{Mg} / \mathrm{Mg}}{ }^{2+}=-2.37 \mathrm{~V}\right.$ and $\mathrm{E}_{\mathrm{Ca} / \mathrm{Ca}}{ }^{2+}=-2.76 \mathrm{~V}$ ) with the $c / c_{\max }$ values determined for different degradation times. The results are plotted in Fig. 7. One can observe a good correlation, thus the application of more inert metal as a node leads to larger stability of studied CPs.

\section{Conclusions}

The method of the preparation of a new $\mathrm{Ca}(\mathrm{Cys})_{2} \mathrm{CP}$ is reported. The structure of this $\mathrm{CP}$ has been also determined as $\mathrm{Ca}(\mathrm{Cys})_{2} \cdot \mathrm{H}_{2} \mathrm{O}$ with the $\mathrm{CN}$ of the $\mathrm{Ca}^{2+}$ as equal to 7 . The stability of studied CPs decreases in the order: $\mathrm{Zn}(\mathrm{C}$ ys $)_{2}>\mathrm{Mg}(\mathrm{Cys})_{2}>\mathrm{Ca}(\mathrm{Cys})_{2} \cdot \mathrm{H}_{2} \mathrm{O}$. It means that the $\mathrm{CN}$ of a metal cation is not a decisive factor influencing the stability of studied CPs in water. However, the presence of water molecule in the first coordination shell, observed for $\mathrm{Ca}(\mathrm{Cys})_{2} \cdot \mathrm{H}_{2} \mathrm{O}$, can be the factor decreasing this $\mathrm{CP}$ stability.

The methods used for the study of CPs stability should have been complementary, like XRD and ATR-FTIR. The results for studied nonporous CPs show, that the harshness of exposure is different than for porous CPs. Thus, our results show that immersion in water at $20^{\circ} \mathrm{C}(\mathrm{ST}-4$ of the original procedure) is more drastic for studied CPs than the harsh humid conditions (ST-5 the original Gelfand and Shimizu procedure). Therefore the order of both stages should be exchanged and we propose the following arrangement: ST-1: $20{ }^{\circ} \mathrm{C}-20 \%$ R.H., ST-2: $25{ }^{\circ} \mathrm{C}-50 \%$ R.H., ST-3: $50{ }^{\circ} \mathrm{C}-50 \%$ R.H., ST-4: $80{ }^{\circ} \mathrm{C}-90 \%$ R.H., ST-5: $20{ }^{\circ} \mathrm{C}$-immersion in $\mathrm{H}_{2} \mathrm{O}$, ST-6: $100^{\circ} \mathrm{C}$-immersion in $\mathrm{H}_{2} \mathrm{O}$. Moreover it is proved that $24 \mathrm{~h}$ treatment in the case of nonporous CPs is insufficient to test their stability. We propose at least $96 \mathrm{~h}$ period of testing. The results of kinetic measurements (ST-5) correlate well with the standard reduction potentials leading to the conclusion that the application of more inert metal as a node leads to larger stability of studied CPs.

Acknowledgements The authors gratefully acknowledge financial support by the Polish National Science Centre (NCN) Grant OPUS 9 no. 2015/17/B/ST5/01446.

Open Access This article is distributed under the terms of the Creative Commons Attribution 4.0 International License (http://creativeco mmons.org/licenses/by/4.0/), which permits unrestricted use, distribution, and reproduction in any medium, provided you give appropriate credit to the original author(s) and the source, provide a link to the Creative Commons license, and indicate if changes were made.

\section{References}

Al-Janabi, N., Alfutimie, A., Siperstein, F.R., Fan, X.: Underlying mechanism of the hydrothermal instability of $\mathrm{Cu}_{3}(\mathrm{BTC})_{2}$ metalorganic framework. Front. Chem. Sci. Eng. 10, 103-107 (2016)
Altomare, A., Caliandro, R., Camalli, M., Cuocci, C., Giacovazzo, C., Moliterni, A.G.G., Rizzi, R.: Automatic structure determination from powder data with EXPO2004. J. Appl. Crystallogr. 37, 1025-1028 (2004)

Altomare, A., Camalli, M., Cuocci, C., da Silva, I., Giacovazzo, C., Moliterni, A.G.G., Rizzi, R.: Space group determination: improvements in EXPO2005. J. Appl. Crystallogr. 38, 760-767 (2005)

Bellarosa, L., Calero, S., Lopez, N.: Early stages in the degradation of metal-organic frameworks in liquid water from firstprinciples molecular dynamics. Phys. Chem. Chem. Phys. 14, 7240-7245 (2012)

Bezverkhyy, I., Weber, G., Bellat, J.P.: Degradation of fluoride-free MIL-100(Fe) and MIL-53(Fe) in water: effect of temperature and pH. Microporous Mesoporous Mater. 219, 117-124 (2016)

Cychosz, K.A., Matzger, A.J.: Water stability of microporous coordination polymers and the adsorption of pharmaceuticals from water. Langmuir. 26, 17198-17202 (2010)

De Toni, M., Jonchiere, R., Pullumbi, P., Coudert, F.X., Fuchs, A.H.: How can a hydrophobic MOF be water-unstable? Insight into the hydration mechanism of IRMOFs. Chem. Phys. Chem. 13, 3497-3503 (2012)

DeCoste, J.B., Peterson, G.W., Jasuja, H., Glover, T.G., Huang, Y., Walton, K.S.: Stability and degradation mechanisms of metalorganic frameworks containing the $\mathrm{Zr}_{6} \mathrm{O}_{4}(\mathrm{OH})_{4}$ secondary building unit. J. Mater. Chem. A. 1, 5642-5650 (2013)

Dolomanov, O.V., Bourhis, L.J., Gildea, R.J., Howard, J.A.K., Puschmann, H.: OLEX2: a complete structure solution, refinement and analysis program. J. Appl. Crystallogr. 42, 339-341 (2009)

Doonan, C., Riccò, R., Liang, K., Bradshaw, D., Falcaro, P.: Metalorganic frameworks at the biointerface: synthetic strategies and applications. Acc. Chem. Res. 50, 1423-1432 (2017)

Ferrer, P., da Silva, I., Rubio-Zuazo, J., Castro, G.R.: Synthesis and crystal structure of the novel metal organic framework $\mathrm{Zn}\left(\mathrm{C}_{3} \mathrm{H}_{5} \mathrm{NO}_{2} \mathrm{~S}\right)_{2}$. Powder Diffr. 29, 366-370 (2014)

Gelfand, B.S., Shimizu, G.K.H.: Parameterizing and grading hydrolytic stability in metal-organic frameworks. Dalton Trans. 45, 3668-3678 (2016)

Guo, P., Dutta, D., Wong-Foy, A.G., Gidley, D.W., Matzger, A.J.: Water sensitivity in $\mathrm{Zn}_{4} \mathrm{O}$-based MOFs is structure and history dependent. J. Am. Chem. Soc. 37, 2651-2657 (2015)

Han, S., Huang, Y., Watanabe, T., Nair, S., Walton, K.S., Sholl, D.S., Meredith, J.C.: MOF stability and gas adsorption as a function of exposure to water, humid air, $\mathrm{SO}_{2}$, and $\mathrm{NO}_{2}$. Microporous Mesoporous Mater. 173, 86-91 (2013)

Harding, M.M., Long, H.A.: The crystal and molecular structure of L-cysteine. Acta Cryst. B 24, 1096-1102 (1968)

Howarth, A.J., Liu, Y., Li, P., Li, Z., Wang, T.C., Hupp, J.T., Farha, O.K.: Chemical, thermal and mechanical stabilities of metalorganic frameworks. Nat. Rev. Mater. 1, 1-15 (2016)

Howarth, A.J., Peters, A.W., Vermeulen, N.A., Wang, T.C., Hupp, J.T., Farha, O.K.: Best practices for the synthesis, activation, and characterization of metal-organic frameworks. Chem. Mater. 29, 26-39 (2017)

Jasuja, H., Huang, Y., Walton, K.S.: Adjusting the stability of metalorganic frameworks under humid conditions by ligand functionalization. Langmuir 28, 16874-16880 (2012)

Jiao, Y., Morelock, C.R., Burtch, N.C., Mounfield, W.P. III, Hungerford, J.T., Walton, K.S.: Tuning the kinetic water stability and adsorption interactions of Mg-MOF-74 by partial substitution with Co or Ni. Ind. Eng. Chem. Res. 54, 12408-12414 (2015)

Katz, A.K., Glusker, J.P., Beebe, S.A., Bock, C.W.: Calcium ion coordination: a comparison with that of beryllium, magnesium, and zinc. J. Am. Chem. Soc. 118, 5752-5763 (1996) 
Lawrence, M.C., Schneider, C., Katz, M.J.: Determining the structural stability of UiO-67 with respect to time: a solid-state NMR investigation. Chem. Commun. 52, 4971-4974 (2016)

Li, P., Chen, J., Zhang, J., Wang, X.: Water stability and competition effects toward $\mathrm{CO}_{2}$ adsorption on metal organic frameworks. Sep. Purif. Rev. 44, 19-27 (2015)

Li, X., Lachmanski, L., Safi, S., Sene, S., Serre, C., Grenèche, J.M., Zhang, J., Gref, R.: New insights into the degradation mechanism of metal-organic frameworks drug carriers. Nat. Sci. Rep. 7, 13142 (2017). https://doi.org/10.1038/s41598-017-13323-1

Lin, W., Hu, Q., Jiang, K., Yang, Y., Yang, Yu, Cui, Y., Qian, G.: A porphyrin-based metal-organic framework as a $\mathrm{pH}$-responsive drug carrier. J. Sol. State Chem. 237, 307-312 (2016)

Lu, P., Wu, Y., Kang, H., Wei, H., Liu, H., Fang, M.: What can $\mathrm{pK}_{\mathrm{a}}$ and NBO charges of the ligands tell us about the water and thermal stability of metal organic frameworks? J. Mater. Chem. A. 2, 16250-16267 (2014)

Ming, Y., Purewal, J., Yang, J., Xu, C., Soltis, R., Warner, J., Veenstra, M., Gaab, M., Müller, U., Siegel, D.J.: Kinetic stability of MOF-5 in humid environments: impact of powder densification, humidity level, and exposure time. Langmuir 31, 4988-4995 (2015)

Mounfield, W.P. III, Tumuluri, U., Jiao, Y., Li, M., Dai, S., Wu, Z., Walton, K.S.: Role of defects and metal coordination on adsorption of acid gases in MOFs and metal oxides: an in situ IR spectroscopic study. Microporous Mesoporous Mater. 227, 65-75 (2016a)

Mounfield, W.P. III, Han, C., Pang, S.H., Tumuluri, U., Jiao, Y., Bhattacharyya, S., Dutzer, M.R., Nair, S., Wu, Z., Lively, R.P., Sholl, D.S., Walton, K.S.: Synergistic effects of water and $\mathrm{SO}_{2}$ on degradation of MIL-125 in the presence of acid gases. J. Phys. Chem. C 120, 27230-27240 (2016b)

Pang, S.H., Han, C., Sholl, D.S., Jones, C.W., Lively, R.P.: Facet-specific stability of ZIF-8 in the presence of acid gases dissolved in aqueous solutions. Chem. Mater. 28, 6960-6967 (2016)

Piscopo, C.G., Polyzoidis, A., Schwarzer, M., Loebbecke, S.: Stability of UiO-66 under acidic treatment: opportunities and limitations for post-synthetic modifications. Microporous Mesoporous Mater. 208, 30-35 (2015)

Rietveld, H.M.: A profile refinement method for nuclear and magnetic structures. J. Appl. Crystallogr. 2, 65-71 (1969)
Taddei, M., Ienco, A., Costantino, F., Guerri, A.: Supramolecular interactions impacting on the water stability of tubular metal-organic frameworks. RSC Adv. 3, 26177-26183 (2013)

Tan, K., Zuluaga, S., Gong, Q., Canepa, P., Wang, H., Li, J., Chabal, Y.J., Thonhauser, T.: Water reaction mechanism in metal organic frameworks with coordinatively unsaturated metal ions: MOF-74. Chem. Mater. 26, 6886-6895 (2014)

Tan, K., Nijem, N., Gao, Y., Zuluaga, S., Li, J., Thonhauser, T., Chabal, Y.J.: Water interactions in metal organic frameworks. Cryst. Eng. Commun. 17, 247-260 (2015)

Thompson, P., Cox, D.E., Hastings, J.B.: Rietveld refinement of DebyeScherrer synchrotron X-ray data from Al2O3. J. Appl. Crystallogr. 20, 79-83 (1987)

Todaro, M., Buscarino, G., Sciortino, L., Alessi, A., Messina, F., Taddei, M., Ranocchiari, M., Cannas, M., Gelardi, F.M.: Decomposition process of carboxylate MOF HKUST-1 unveiled at the atomic scale level. J. Phys. Chem. C 120, 12879-12889 (2016)

Wang, L.J., Deng, H., Furukawa, H., Gándara, F., Cordova, K.E., Peri, D., Yaghi, O.M.: Synthesis and characterization of metal-organic framework-74 containing 2, 4, 6, 8, and 10 different metals. Inorg. Chem. 53, 5881-5883 (2014)

Wang, S., Kang, Z., Xu, B., Fan, L., Li, Q., Wen, L., Xin, X., Xiao, Z., Pang, J., Du, X., Sun, D.: Wettability switchable metal-organic framework membranes for pervaporation of water/ethanol mixtures. Inorg. Chem. Commun. 82, 64-67 (2017)

Wiśniewski, M., Bieniek, A., Roszek, K., Czarnecka, J., Bolibok, P., Ferrer, P., da Silva, I., Terzyk, A.P.: Cystine-based MBioF for maintaining the antioxidant-oxidant balance in airways diseases. ACS Med. Chem. Lett. (2018). https://doi.org/10.1021/acsme dchemlett.8b00468

Zhang, Z., Wang, Y., Jia, X., Yang, J., Li, J.: The synergistic effect of oxygen and water on the stability of the isostructural family of metal-organic frameworks $\left[\mathrm{Cr}_{3}(\mathrm{BTC})_{2}\right]$ and $\left[\mathrm{Cu}_{3}(\mathrm{BTC})_{2}\right]$. Dalton Trans. 46, 15573-15581 (2017)

Zuluaga, S., Fuentes-Fernandez, E.M.A., Tan, K., Xu, F., Li, J., Chabal, Y.J., Thonhauser, T.: Understanding and controlling water stability of MOF-74. J. Mater. Chem. A. 4, 5176-5183 (2016) 